\title{
A relevância da enfermagem a mulher vítima de violência doméstica
}

\author{
The relevance of nursing to women victims of domestic violence
}

La relevancia de la enfermería para las mujeres víctimas de violencia doméstica

Mauro Souza dos Santos ${ }^{1 *}$, Maria Gorete Repolho Laurido', Marcela Gonçalves da Silva1, Denizângela Martins Pinto ${ }^{1}$, Jhully do Socorro Reis Farias ${ }^{1}$, Priscilla Caroline de Souza Saraiva Lino ${ }^{1}$, Simone Cristina da Silva Melo'.

\section{RESUMO}

Objetivo: O presente artigo teve como objetivo geral descrever a relevância da enfermagem a mulher vítima de violência doméstica. Métodos: O estudo trata-se de um estudo exploratório, descritivo, do tipo Revisão Integrativa da Literatura. Para coleta de dados, foram utilizadas as bibliotecas virtuais de pesquisa: Biblioteca Científica Eletrônica Online (SCIELO) e Literatura Latino Americana e do Caribe em Ciências da Saúde (LILACS). Resultados: A assistência as vítimas, é necessário a atendimento de qualidade e com atendimento da equipe multiprofissional da forma que possam tratar a lesão, mas também orientar e encaminhar a vítima para os serviços especializados com os atendimentos seguindo o passo a passo. Considerações finais: Sendo assim é de extrema necessidade que as mulheres tenham conhecimento e saibam utilizar seus direitos a fim de se libertarem da violência e da opressão a que estão subjugadas na esfera doméstica, após a promulgação da Lei Maria da Penha, as mulheres passaram a se achar mais empoderadas, mas ainda não é suficiente para que consigam competir com os homens de forma igualitária.

Palavras-chave: Enfermagem, Violência contra a mulher, Família.

\begin{abstract}
Objective: This article aimed to describe the relevance of nursing for women who are victims of domestic violence. Methods: The study is an exploratory, descriptive study, of the type Integrative Literature Review. For data collection, the virtual research libraries were used: Online Electronic Scientific Library (SCIELO) and Latin American and Caribbean Literature in Health Sciences (LILACS). Results: Assistance to victims, it is necessary to provide quality care and assistance from the multidisciplinary team in a way that they can treat the injury, but also guide and refer the victim to specialized services with the assistance following the step by step. Final considerations: So it is extremely necessary that women have knowledge and know how to use their rights in order to free themselves from the violence and oppression to which they are subjugated in the domestic sphere. After the promulgation of the Maria da Penha Law, women started to feel more empowered, but it is still not enough for them to be able to compete with men on an equal basis.
\end{abstract}

Keywords: Nursing, Violence against women, Family.

\section{RESUMEN}

Objetivo: Este artículo tuvo como objetivo describir la relevancia de la enfermería para las mujeres víctimas de violencia intrafamiliar. Métodos: El estudio es un estudio exploratorio, descriptivo, del tipo Revisión de Literatura Integrativa. Para la recolección de datos se utilizaron las bibliotecas virtuales de investigación: Biblioteca Científica Electrónica en Línea (SCIELO) y Literatura Latinoamericana y del Caribe en Ciencias de la Salud (LILACS). Resultados: Asistencia a las víctimas, es necesario brindar una atención y asistencia

${ }^{1}$ Centro Universitário Fametro, Manaus - AM. *E-mail: maurosouza888@gmail.com 
de calidad por parte del equipo multidisciplinario de manera que puedan tratar la lesión, pero también orientar y derivar a la víctima a servicios especializados con la asistencia siguiendo el paso a paso. Consideraciones finales: Por eso es sumamente necesario que las mujeres conozcan y sepan ejercer sus derechos para poder liberarse de la violencia y opresión a las que están sometidas en el ámbito doméstico. Luego de la promulgación de la Ley Maria da Penha, las mujeres comenzaron a sentirse más empoderados, pero todavía no es suficiente para ellos poder competir con los hombres en igualdad de condiciones.

Palabras clave: Enfermería, Violencia contra la mujer, Familia.

\section{INTRODUÇÃO}

A violência foi definida pela Organização Mundial da Saúde (OMS) como uma pratica onde se impõem força e poder, contra qualquer pessoa ou consigo próprio, com intimidações, podendo até chegar a um ato que cause mais danos a integridade do indivíduo, causando sofrimento psicológico, danos físicos, colocando em risco a vida do mesmo (ANDRADE PO, et al, 2016).

A violência contra a mulher, em toda a suas formas, é um fenômeno que atinge mulheres de diferentes classes sociais, origens, religiões, estado civil, escolaridade ou etnia. Uma em cada três mulheres relatam agressões físicas pelo companheiro atual ou anterior e uma de cada cinco mulheres são vítimas de violência sexual ao longo da vida, configurando uma desigual relação de gênero e poder em proporções epidêmicas (GUIMARÃES MC e PEDROZA RL, 2015).

Por ter se tornado um problema de saúde pública que vem aumentando drasticamente, a Violência Doméstica Contra a Mulher (VDCM) passou a ter um olhar tanto da ordem pública como do corpo social cientifico. São situações que ocorrem a milhares de anos atrás, que envolvem costumes, tradições e até mesmo crenças, que estão associados a esses eventos, que trazem a interpretação das ocorrências, inclusive para estudo na área da saúde (SILVA CD, et al, 2016).

A violência está relacionada a uma série de fatores, como a diferença no nível social, sexo e pelas distinções em foram estabelecidas por muitos anos e se tornaram ramificadas. A VDCM foi classificada como um problema de saúde pública pela OMS, devido ao grande aumento de casos, porém é lamentável que poucos profissionais de saúde lidam com esse tipo de circunstâncias, de forma que as agressões domesticas passam a terem menos importância (ACOSTA DF, 2018).

Por estar se apresentando como um problema de saúde pública, a VDCM precisa de um olhar voltado para esse contexto pela equipe de saúde, com competências de enfermagem diante do atendimento a essas mulheres vítimas de violência, com as melhores formas de posicionamentos e de maneira humanista, para consigam prestar a assistência adequada à vítima. Dos profissionais de saúde: manejo e prevenção dessas situações (LUCENA KD, et al, 2016).

A violência de gênero descende do patriarcado perante uma organização social que prioriza o masculino ao estabelecer papéis sociais no quais os homens possuem o poder perante sua mulher e filhos (as) e devem demonstrar/ confirmar seu domínio através da violência, estabelecendo-se como principal ator da violência pública ao ser o homem naturalmente inclinado a atos violentos (TANNURI JG e SILVA MS, 2019).

A partir do ano de 2006, foi vigorada a Lei 11.340, chamada de Lei Maria da Penha, com a intenção de reprimir a violência doméstica (VD) e familiar contra as mulheres, em seu Artigo $5^{\circ}$ do Capítulo 1 , a violência doméstica e intrafamiliar constitui "qualquer ação ou omissão contra a mulher e baseada no gênero que lhe cause morte, lesão, sofrimento físico, sexual ou psicológico ou dano moral ou patrimonial", podendo ser na unidade doméstica, âmbito familiar independente de qualquer relação íntima de afeto ou orientação sexual. (BANDEIRA LM e ALMEIDA TM, 2015).

Ainda com a lei em vigor, mesmo assim existem mulheres que omitem o ato de violência sofrido, continuam convivendo com o agressor, buscando por socorro quando a situação chega a casos em que a vítima sofre uma violência de intensa gravidade. O profissional de saúde deve estar atento para os 
possíveis sinais que possam indicar VDCM, já que, após a agressão sofrida, a vítima irá ter seu primeiro contato com o profissional para prestar as devidas assistências (SOUZA MC e BARACHO LF, 2015).

Com a Lei Maria da Penha, formularam planos e políticas destinadas a proteger as mulheres e promoveram melhoria na qualidade da prestação dos serviços. Mesmo assim, infelizmente, com o respaldo da lei, as vítimas ainda enfrentam desafios para lidar com a violência que sofrem, portanto, medidas básicas de proteção dessas vítimas são essenciais (MOREIRA RV, et al, 2015).

Os programas e políticas que são direcionados a atenção à violência contra a mulher projetam medidas que proporcionem um bom acolhimento, uma assistência de qualidade e o direcionamento dessas vítimas aos outros procedimentos cabíveis. Conforme o Ministério Público, acerca da questão, cabe ressaltar que alguns dados estatísticos relevantes e divulgados, entre os anos de 2017 a 2017 a proporção de mulheres vítimas de violência variou discretamente de $28,6 \%$ para $27,4 \%$ revelando que, ao longo do período, cerca de 16 milhões de mulheres sofreram algum tipo de violência, sendo esta considerada muito elevada (HASSE M e VIEIRA EM, 2014).

Ainda nesse contexto, de acordo com o Fórum Brasileiro de Segurança Pública (FBSP), o número de primeiros socorros para mulheres aumentou dramaticamente, de 6.775 para 9.817 entre março de 2019 e março de 2020. Por outra forma, o número de boletins de ocorrência caiu fortemente, com queda de $28,6 \%$, o que mostra que há uma série de entraves. No contexto da pandemia de 2020, as vítimas enfrentarão queixas. Nesse sentido, as seguintes estatísticas de redução merecem atenção: Ceará $(-29,1 \%)$; Mato Grosso (-21,9\%); Pará (13,2\%); Rio Grande do Sul (-9,4\%) (BRASIL, 2020).

Portanto, os profissionais de enfermagem devem estar sempre capacitados para melhorar a qualidade das mulheres vítimas de violência e prestar um atendimento claro para que se sintam seguras, acolhidas, respeitadas e, o mais importante, para atender às suas necessidades pessoais. Orientar-se sempre pelas ferramentas básicas propostas nas políticas públicas de saúde e nas legislações existentes para proteger adequadamente as vítimas e prevenir possíveis danos no futuro (PORTO KB, 2020).

Além de realizar procedimentos técnicos e de coleta de dados e levar as vítimas aos serviços de apoio social ou outras instituições necessárias, os profissionais de enfermagem também devem realizar testes de memória, exames laboratoriais e exames físicos para identificação de sinais físicos e comportamentais. 0 enfermeiro precisa estar plenamente preparado para prestar atendimento humanizado às vítimas de violência sexual, com base no diálogo e na confiança (PAULA SS, 2019).

Diante do exposto, reflete a importância do acolhimento e atendimento personalizado, e enfatiza as necessidades de toda mulher vítima de violência sexual, pois, dessa forma, ela se sente mais segura, facilitando assim o diálogo entre a enfermeira e a vítima. Quando o cuidado é efetivo, pode favorecer o diálogo entre o enfermeiro e a vítima, possibilitando que a vítima a compreenda e ouça com atenção e união, o que é característico da qualidade do cuidado. Portanto, o acolhimento ao trabalho da enfermagem está na implantação de uma atitude humanizada, que se manifesta na conduta de aceitar, ouvir e tratar sua dor (MACHADO LP e FREITAG VL, 2021).

O objetivo geral do presente artigo é descrever a relevância da enfermagem a mulher vítima de violência doméstica.

\section{MÉTODOS}

Trata-se de um estudo exploratório, descritivo e do tipo de Revisão Integrativa da Literatura (RIL). Para coleta de dados, foram utilizadas as bibliotecas virtuais de pesquisa: Biblioteca Científica Eletrônica Online (SCIELO) e Literatura Latino Americana e do Caribe em Ciências da Saúde (LILACS) mediantes os seguintes descritores: "Enfermagem", "Violência contra a mulher" e "Família".

Como critérios de elegibilidade foram selecionados artigos originais, disponibilizados gratuitamente, em língua portuguesa e língua inglesa, com recorte metodológico de 2010 a 2021, que tratam do tema pesquisado. 
Critérios de inelegibilidade foram: Artigos em formato de resumos, com textos incompletos, monografias, dissertações de mestrado e teses de doutorado com relação aos critérios éticos, seguiremos as normativas referentes à boa conduta em pesquisa, livre de plágios e de acordo com a Portaria 466/2010.

Os artigos foram selecionados de acordo com os critérios de elegibilidade e inelegibilidade a partir dos com os títulos, posteriormente foi realizada a análise de resumos e finalmente os artigos foram lidos na integra, sendo elaborado um instrumento para a coleta de informações direto das bases de dados.

O total de artigos científicos consultados para a realização dos objetivos propostos na presente pesquisa, à revisão foram realizados com 54 artigos, descartados 18 artigos, e utilizados 36 artigos publicados a partir do ano 2010 ao ano de 2021, tratavam do tema desenvolvido no artigo.

Figura 1 - Fluxograma de critério de inclusão.

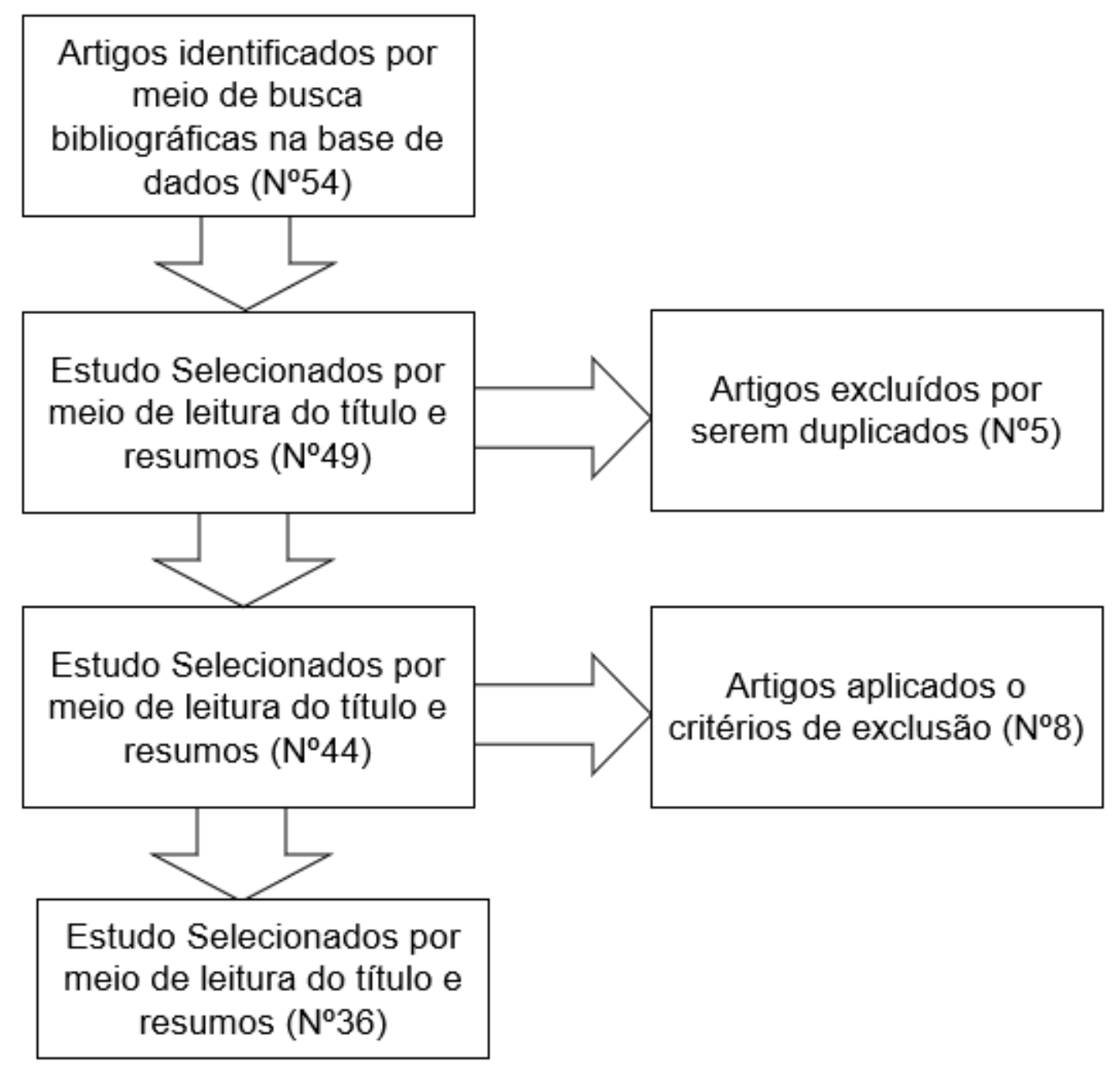

Fonte: Santos MS, et al., 2021.

\section{RESULTADOS E DISCUSSÃO}

O total de artigos apresentados na presente pesquisa de revisão integrativa foram de 54 artigos, assim foram aplicados os critérios de exclusão, sendo 18 artigos descartados, e correspondendo o total de 36 artigos empregados no trabalho, publicados a partir do ano 2010 ao ano de 2020. Para a presente seção foram usados 8 artigos (Quadro 1). 
Quadro 1 - Principais resultados.

\begin{tabular}{|c|c|c|c|c|}
\hline Autor & Ano & Tipo de estudo & Idioma & $\begin{array}{l}\text { Principais resultados } \\
\end{array}$ \\
\hline $\begin{array}{l}\text { ALCÂNTARA PP, } \\
\text { et al. }\end{array}$ & 2019 & $\begin{array}{l}\text { Pesquisa } \\
\text { descritiva }\end{array}$ & Português & $\begin{array}{l}\text { Portanto, a violência contra a mulher é um grave } \\
\text { problema social que requer consciência, apoio e } \\
\text { atenção de todos os setores da sociedade. }\end{array}$ \\
\hline $\begin{array}{l}\text { MACEDO CS, } \\
\text { ALMEIDA MA. }\end{array}$ & 2017 & $\begin{array}{l}\text { Pesquisa } \\
\text { descritiva }\end{array}$ & Português & $\begin{array}{l}\text { Portanto, a violência contra a mulher é um grave } \\
\text { preconceito contra a mulher, e a ignorância é a } \\
\text { base da violência doméstica, pois, elas mostram } \\
\text { que esse fato é completamente insatisfatório. }\end{array}$ \\
\hline CAMPOS $\mathrm{CH}$. & 2015 & $\begin{array}{l}\text { Revisão de } \\
\text { Literatura }\end{array}$ & Português & $\begin{array}{l}\text { Nesse sentido, a transferência da dominação } \\
\text { doméstica em caso de morte do senhor permitia } \\
\text { que seu sucessor adquirisse, entre outras coisas, } \\
\text { por exemplo, o direito do uso sexual das mulheres } \\
\text { de seu predecessor. }\end{array}$ \\
\hline $\begin{array}{l}\text { COSTA BA, } \\
\text { ARCELO AA }\end{array}$ & 2018 & $\begin{array}{l}\text { Revisão de } \\
\text { Literatura }\end{array}$ & Português & $\begin{array}{l}\text { A violência de gênero que está relacionada a uma } \\
\text { questão sociológica, onde papeis atribuídos a } \\
\text { homens e mulheres se diferem. }\end{array}$ \\
\hline SILVA AC, et al. & 2014 & $\begin{array}{l}\text { Revisão } \\
\text { Sistemática }\end{array}$ & Português & $\begin{array}{l}\text { A violência é um problema social e de saúde } \\
\text { pública que atinge a qualidade de vida e coloca } \\
\text { em risco o desenvolvimento da população, } \\
\text { independente de raça, idade, educação ou } \\
\text { condições sociais. A violência é um tema muito } \\
\text { relevante, uma vez que, no início do século XXI, } \\
\text { atingiu proporções epidêmicas, com importância } \\
\text { na atenção à saúde }\end{array}$ \\
\hline LIMA LAA, et al. & 2017 & $\begin{array}{l}\text { Revisão } \\
\text { integrativa }\end{array}$ & Português & $\begin{array}{l}\text { A assistência de enfermagem é o acolhimento, } \\
\text { que tem sido utilizado como ferramenta que auxilia } \\
\text { na investigação fazendo com que a cliente sinta- } \\
\text { se mais confortável mediante o sofrimento. }\end{array}$ \\
\hline $\begin{array}{l}\text { SANTOS WJ, et } \\
\text { al }\end{array}$ & 2018 & $\begin{array}{l}\text { Pesquisa } \\
\text { qualitativa }\end{array}$ & Português & $\begin{array}{l}\text { A violência contra a mulher foi legalizada, aceita e } \\
\text { tolerada, o que é inerente / intrínseco à mulher. }\end{array}$ \\
\hline $\begin{array}{l}\text { CORTES LF, } \\
\text { PADOIN SM. }\end{array}$ & 2016 & $\begin{array}{l}\text { Pesquisa } \\
\text { descritiva }\end{array}$ & Português & $\begin{array}{l}\text { A assistência, é necessário que o enfermeiro e os } \\
\text { profissionais de saúde sejam hábeis perante a } \\
\text { avaliação inicial e identificação dos sintomas, } \\
\text { evitando assim desconforto um acolhimento } \\
\text { imediato para a melhor destes agravos. }\end{array}$ \\
\hline
\end{tabular}

Fonte: Santos MS, et al., 2021.

De acordo com Alves AM e Rodrigues NF (2010) a violência doméstica é um assunto histórico, cultural e civil presente no cenário brasileiro, sendo assim um problema que persiste por séculos, oriundo desde a Antiguidade com escritos bíblicos no qual a mulher era foi construída da costela de um homem, vindo depois da existência dele para esta lhe fazer companhia. Ainda de acordo com o mesmo autor, desse modo à mulher culturalmente nasce submissa as necessidades do homem (MACEDO CS e ALMEIDA MA, 2017).

Tanto no Brasil Colônia, Brasil Império e Brasil República, as relações familiares seguiam o padrão familiar europeu português, onde o homem era o provedor e a mulher deveria ser submissa ao marido, cuidar da casa e dos filhos. Elas tinham um espaço limitado de atuação, sempre dependendo e submetendo-se aos mandos de seus maridos (DAY VP, et al, 2003).

Esse padrão familiar em que o homem se torna a figura máxima de poder é conhecido como patriarcalismo ou patriarcado, que esteve presente em toda a história familiar brasileira, e de acordo com Rezende DL (2015), a sua característica é que o poder do poder familiar se materializa na propriedade, pelo que se pode afirmar que o chefe do agregado familiar possui a propriedade dos seus filhos, escravos, esposas e servos, podendo dispor dela como propriedade a qualquer momento necessário.

Nesse sentido, a transferência do domínio doméstico em caso de morte do proprietário permite que seu sucessor obtenha, entre outros direitos, por exemplo, o direito ao uso sexual das mulheres de suas predecessoras (REZENDE DL, 2015). 
Sendo assim o marido, tal como pai, sentia-se no dever de punir com violência sua esposa quando este era desobedecido, na época tal agressão não estaria autorizada pela legislação e nem se fundamentava nas regras de proteção aos costumes, a título dessa submissão feminina ao marido e chefe da família, $p$ Código Civil de 1916 perpetuava a submissão da esposa ao marido, ao consagrar que a mulher casada dependeria da autorização dele ou do arbítrio do juiz para sair sozinha. Para melhor compreensão dos tipos de violências contra as mulheres, é imprescindível o conceito de violência doméstica que traz à tona o Ordenamento Jurídico brasileiro, tal violência pode ser entendida como o ato de desrespeito à vítima, que sofre uma série de agressões sendo física ou moral, sendo assim entende-se que violência doméstica contra a mulher são: a violência física, psicológica, patrimonial e moral (CAMPOS CH, 2015).

Sendo assim o marido, tal como pai, sentia-se no dever de punir com violência sua esposa quando este era desobedecido, na época tal agressão não estaria autorizada pela legislação e nem se fundamentava nas regras de proteção aos costumes, a título dessa submissão feminina ao marido e chefe da família, o Código Civil de 1916 perpetuava a submissão da esposa ao marido, ao consagrar que a mulher casada dependeria da autorização dele ou do arbítrio do juiz para sair sozinha (ANDRADE VR, 2015). No Código Civil de 2002 surgiu em um ambiente mais igualitário, conferindo às mulheres um status ativo e independente. Sua obediência ao povo desapareceu no campo legislativo (CHEREM LM, 2019).

Para melhor compreender os tipos de violência contra a mulher, é fundamental apresentar os conceitos de violência doméstica no ordenamento jurídico brasileiro, que pode ser considerada um ato de desrespeito à vítima de violência física ou física. De violações. Portanto, entende-se que a violência doméstica contra a mulher é: violência física, psicológica, hereditária e moral (CAMPOS $\mathrm{CH}, 2015)$.

Incluindo também a violência de gênero que está relacionada a uma questão sociológica, onde papeis atribuídos a homens e mulheres se diferem. Onde um grupo tem mais poder que outro, por questão de gênero, questão histórica de determinação social dos papéis masculinos e femininos atribuídos pesos diferenciados, supervalorizando um e subvalorizando o outro (COSTA BA e ARCELO AA, 2018).

A Organização Mundial de Saúde (OMS) o incidente violento é considerado uma parte possível da própria história da humanidade e seu impacto é amplo e variado, em todo o mundo. No entanto, a violência é um problema social e de saúde pública, independentemente de raça, idade, escolaridade ou condição social, ela afetará a qualidade de vida e colocará em risco o desenvolvimento populacional. A violência é um tema muito relevante, pois no início do século 21, a violência atingiu proporções epidêmicas e tem grande importância na saúde (SILVA AC, et al, 2014).

Muitas mulheres que sofrem a violência doméstica e não conseguem se afastar de seus parceiros, sendo os motivos identificados como sendo pelo fato de depender financeiramente do marido, ou por simplesmente terem medo, ocorre então as consequências psicológicas que podem ser visíveis através do sintomas de: insônia, pesadelos, falta de concentração, irritabilidade, falta de apetite, depressão, ansiedade, síndrome do pânico, stress pós-traumático e comportamentos autodestrutivos na maioria das vezes (ANDRADE VR, 2015).

Segundo Alcântara PP, et al., (2011) e Lima AA, et al. (2017), um dos componentes da assistência de enfermagem é o acolhimento, que tem sido utilizado como ferramenta que auxilia na investigação fazendo com que a cliente sinta-se mais confortável mediante o sofrimento.

$\mathrm{O}$ acolhimento é a primeira medida que o serviço de pronto atendimento à vítima deve oferecer. Tem como princípio primordial ser isento de prejulgamentos e valores morais, e deve ser oferecido em local próprio e privativo. Devem ser abordadas questões diretas sobre atividades sexuais, uso de substâncias lícitas e ilícitas e prostituição, realizando-se a avaliação da indicação da profilaxia de emergência (PE), conforme protocolo terapêutico. Destaca-se que o primeiro atendimento à vítima independe de realização de Boletim de Ocorrência (B.O) (MACEDO CS e ALMEIDA MA, 2017).

Neste sentido, Santos WJ, et al, (2018) e Cortes LF e Pandoin SM (2016), assim que a vítima procurar assistência, é necessário que o enfermeiro e os profissionais de saúde sejam hábeis perante a avaliação inicial e identificação dos sintomas, evitando assim desconforto um acolhimento imediato para a melhor destes agravos. 
Sendo assim, como os enfermeiros de emergências exercem a linha de frente ao cuidado às vítimas de violência, é imprescindível que esses profissionais sejam qualificados a prestar o atendimento adequado a essas vítimas, conhecendo os direitos que lhe são assegurados, evitando a revitimização, e promovendo a adequada preservação das provas depositadas nas vítimas, até que a mesma seja atendida por profissional especialista forense para recolha e preservação de provas e vestígios. Essa qualificação pode e deve ser realizada pelo enfermeiro forense (MELO RA, et al., 2016).

Segundo Silva EB, et al. (2015) em se tratando ainda de assistência as vítimas, é necessário a atendimento de qualidade e com atendimento da equipe multiprofissional da forma que possam tratar a lesão, mas também orientar e encaminhar a vítima para os serviços especializados com os atendimentos seguindo o passo a passo.

Em o atendimento pode ser dividido em duas fases, onde a 1 a (imediata e emergencial) contemplará: tratamento e diagnóstico; amparo multiprofissional; coleta de vestígios; profilaxia antirretroviral e de profilaxia da gravidez; exame de HIV (acompanhamento e terapia); e esclarecimento quanto ao direito de registro de ocorrência e encaminhamento para os órgãos do sistema judiciário competente (delegacias da mulher e Instituto Médico Legal - IML). A $2^{a}$ fase (integral): assegurar o direito a interrupção legal da gestação nos casos de estupro (KNOLL A e DE AGUIAR GB, 2020).

Segundo Acosta DF, et al. (2015) e Amarijo CP, et al. (2018) perante os diante do atendimento prestado a mulher vítima de violência, os cuidadores na linha de frente precisam tem respeito, ética e a conduta correta independente dos fatos, sendo assim estimular a vítima perante a denúncia, porém algumas situações o desafio do atendimento é visível, visto que tais profissionais se sentem impotentes em relação ao agressor, verifica-se também a importância do acolhimento e acompanhamento familiar, visto que na maioria das vezes as vítimas sempre se sentem amparadas pela figura feminina dentro da sua família.

Para a mulher sobrevivente de qualquer tipo de violência, deve ser assegurado acompanhamento psicológico, a fim de superar os traumas vivenciados, sendo assim a violência sexual é uma das formas de violência mais traumatizantes. O fato de a vítima estar sensível e frágil devido aos fatos vivenciados, faz com que o profissional precise ter empatia, e ser sensível às falas referenciadas. Tal profissional deve transmitir confiança à mulher de forma que ela se sinta segura a relatar a violência (BARROS LM, et al, 2015).

Segundo Vinsentin F, et al. (2015) e Netto LA, et al. (2014) a conversa do enfermeiro é identificada como o diálogo sendo o divisor de águas perante a assistência direta dessa vítima, a abordagem desafiante, as orientações e o respeito são impostos devido ao encorajamento destas mulheres, de forma que vençam o desafio encontrado.

O Ministério da Saúde (2014) e o Ministério da Justiça (2014) expressaram claramente sua busca por orientar a prática de enfermagem e padronizar, fornecendo o suporte para a atuação dos profissionais, com orientações precisas às vítimas e difundir técnicas de enfermagem humanizada para pessoas em situação de violência por meio de registros de informações e padrão de coleta dados. As orientações têm impacto em âmbito nacional e recomenda que, por meio do esclarecimento dos diversos serviços, se fortaleça uma rede integral de atendimento à população, principalmente às mulheres, em situações de violência (HASSE M e VIEIRA EM, 2014).

\section{CONSIDERAÇÕES FINAIS}

O problema da violência doméstica e familiar cometida contra as mulheres percorre todos os níveis sociais e independe de raça, idade, profissão, escolaridade, religião e etc., sendo assim muitas vezes tornase comum na vida dos casais, torna-se rotineiro, com ênfase no relacionamento familiar ocorrendo assim de modo geral a discriminação dentro de casa. Após reivindicações e denúncias, principalmente por movimentos feministas, a violência contra a mulher deixou de ser encarada como um problema familiar, ou melhor, um problema privado, para ser classificada como um grave problema social, sendo este necessitado da intervenção do Estado para demandar mais segurança às mulheres e reduzir drasticamente seus índices que hoje em dia ainda são bastante elevados. 


\section{REFERÊNCIAS}

1. ACOSTA DF, et al. Representações sociais de enfermeiras acerca da violência doméstica contra a mulher: estudo com abordagem estrutural. Revista Gaúcha de Enfermagem, 2018; 39, 1-8.

2. ALCÂNTARA PP, et al. Mulheres vítimas de violência atendidas em um centro de referência de atendimento à mulher. SANARE-Revista de Políticas Públicas, 2019; 18(2).

3. ALVES AM, RODRIGUES NF. Determinantes sociais e económicos da Saúde Mental. Revista Portuguesa de Saúde Pública, 2010; 28(2), 127-131.

4. AMARIJO CP, et al. Assimilação teórica e prática da violência doméstica: profissionais de enfermagem atendendo vítimas na atenção primária. Revista Ẻnfermagem UERJ, 2018; 26, 33874.

5. ANDRADE PO, et al. Fatores associados à violência obstétrica na assistência ao parto vaginal em uma maternidade de alta complexidade em Recife, Pernambuco. Revista Brasileira de Saúde Materno Infantil, 2016; 16(1), 29-37.

6. ANDRADE VR. A soberania patriarcal: o sistema de justiça criminal no tratamento da violência sexual contra a mulher. Seqüência: Estudos Jurídicos e Políticos, 2005; 26(50), 71-102.

7. BANDEIRA LM, ALMEIDA TM. Vinte anos da Convenção de Belém do Pará e a Lei Maria da Penha. Revista Estudos Feministas, 2015; 23(2), 501-517.

8. BARROS LM, et al. Vivência de (des) acolhimento por mulheres vítimas de estupro que buscam os serviços de saúde. Revista da Escola de Enfermagem da USP, 2015; 49(2), 0193-0200.

9. BRASIL. Lei $n^{0} 10.778$, de 24 de novembro de 2003 . Estabelece a notificação compulsória, no território nacional, do caso de violência contra a mulher que for atendida em serviços de saúde públicos ou privados. Diário Oficial da União, Brasília, 24 de novembro de 2003. Disponível em: http://www.planalto.gov.br/ccivil_03/leis/2003/110.778.htm. Acesso em: 26 de março de 2021.

10. BRASIL. Portaria GM no 154, de 24 de janeiro de 2008. Cria os Núcleos de Apoio à Saúde da Família - NASF. Diário Oficial da União, Brasília, 24 de janeiro de 2008. Disponível em: http://bvsms.saude.gov.br/bvs/saudelegis../gm/2008/prt0154_24_01_2008.html. Acesso em 26 de março de 2021.

11. BRASIL. Violência doméstica durante a pandemia de Covid-19. Forum Brasileiro de Segurança Pública, 2020.

12. CAMPOS CH. Desafios na implementação da Lei Maria da Penha. Revista Direito GV, 2015; 11(2), $391-406$.

13. CHEREM LM. A mulher segundo o Código Civil de 1916. 2019.

14. CORTES LF, PADOIN SM. Intencionalidade da ação de cuidar mulheres em situação de violência: contribuições para a Enfermagem e Saúde. Escola Anna Nery, 2016; 20(4), 1-9.

15. COSTA BA, ARCELO AA. Autorreconhecimento e reconhecimento social de gênero como dispositivos de subjetivação bastantes para acesso às medidas protetivas da lei no 11.340/2006. Revista de Direitos e Garantias Fundamentais, 2018; 19(2), 99-122.

16. DAY VP, et al. Violência doméstica e suas diferentes manifestações. Revista de psiquiatria do Rio Grande do Sul, 2003; 25 , 9-21.

17. GUIMARÃES MC, PEDROZA RL. Violência contra a mulher: problematizando definições teóricas, filosóficas e jurídicas. Psicologia \& Sociedade, 2015; 27(2), 256-266.

18. HASSE M, VIEIRA EM. Como os profissionais de saúde atendem mulheres em situação de violência? Uma análise triangulada de dados. Saúde em Debate, 2014; 38(102), 482-493.

19. KNOLL A, DE AGUIAR GB. O propósito desvirtuado das varas de violência doméstica na atualidade. Brazilian Journal of Development, 2020; 6(7), 161-177.

20. LIMA LAA, et al. Assistência de enfermagem às mulheres vítimas de violência doméstica. Rev. enferm. UFPI, 2017; 65-68.

21. LUCENA KD, et al. Analysis of the cycle of domestic violence against women. Journal of Human Growth and Development, 2016; 26(2), 139-146.

22. MACEDO CS, ALMEIDA MA. O Acolhimento de Mulheres Vítimas de Violência Doméstica. ID on line Revista De Psicologia, 2017; 10(33), 166-176.

23. MACHADO LP, FREITAG VL. Cuidado de enfermagem a mulher vítima de violência sexual: uma revisão integrativa da literatura. Research, Society and Development, 2021;10(2), 1-16.

24. MELO RA, et al. Violência doméstica na percepção de enfermeiros de serviço de emergência. Violência doméstica na percepção de enfermeiros de serviço de emergência. Revista Ciência \& Saberes-UniFacema, 2016; 2(3), 221-228.

25. MOREIRA RV, et al. Uma reflexão sobre a participação da mulher na sociedade e a aplicação da Lei no 11.340/2006 (Lei Maria da Penha) no contexto da violência. Revista Internacional de Investigación en Ciencias Sociales, 2015; 11(2), 259272.

26. NETTO LA, et al. Violence against women and its consequences. Acta Paulista de Enfermagem, 2014; 27(5), $458-464$.

27. PAULA SS, et al. A importância da atuação do enfermeiro às vítimas de violência sexual. Revista Jurídica Uniandrade, 2019; 30(1), 59-72.

28. PORTO KB, et al. Sistematização da assistência de enfermagem no atendimento à mulher vítima de violência. Revista Eletrônica Acervo Saúde, 2020; 12(11), 1-10.

29. REZENDE DL. Patriarcado e formação do Brasil: uma leitura feminista de Oliveira Vianna e Sérgio Buarque de Holanda. Pensamento Plural, 2015(17), 07-27.

30. SANTOS WJ, et al. Violência Doméstica Contra a Mulher Perpetrada por Parceiro Íntimo: Representações Sociais de Profissionais da Atenção Primária à Saúde, 2018; 10(3), 770-777.

31. SILVA AC, et al. O que se sabe sobre o homem autor de violência contra a parceira íntima: uma revisão sistemática. Revista Panamericana de Salud Publica, 2014; 35, 278-283.

32. SILVA CD, et al. Conteúdos representacionais da violência doméstica contra a mulher entre discentes de enfermagem. Revista Eletrônica de Enfermagem, (2016); 18.

33. SILVA EB, et al. Violência contra a mulher e a prática assistencial na percepção dos profissionais da saúde. Texto \& Contexto-Enfermagem, 2015; 24(1), 229-237.

34. SOUZA MC; BARACHO LF. A Lei Maria da Penha: égide, evolução e jurisprudência no Brasil. Revista Eletrônica do Curso de Direito - PUC Minas Serro,2015; (11), 79-106.

35. TANNURI JG, SILVA MS. Família homoparental: enfrentando a vitalidade do patriarcado. Revista Linhas, 2019; 20(43), 256-271.

36. VISENTIN F, et al. Women's primary care nursing in situations of gender violence. Investigación y Educación en Enfermería, 2015; 33(3), 556-564. 